\title{
Fatores que influenciam na longevidade de restaurações diretas: Uma revisão
}

\section{integrativa}

\author{
Factors that influence the longevity of direct restorations: An integrative review \\ Factores que influyen en la longevidad de las restauraciones directas: Una revisión integradora
}

Recebido: 15/05/2021 | Revisado: 25/05/2021 | Aceito: 15/06/2021 | Publicado: 29/06/2021

\author{
Emerson de Sousa Pinheiro \\ ORCID: https://orcid.org/0000-0003-3844-470X \\ Universidade de Brasília, Brasil \\ E-mail: emersonpisousa@gmail.com \\ Marcelly da Conceição Seixas Abreu Gomes \\ ORCID: https://orcid.org/0000-0002-2632-0219 \\ Instituto Florence de Ensino Superior, Brasil \\ E-mail: marcellyseixasa08@gmail.com \\ Susana Raquel dos Santos Ferreira \\ ORCID: https://orcid.org/0000-0001-6444-9374 \\ Universidade de Brasília, Brasil \\ E-mail: susanarsf@outlook.com \\ Camila Roxo Silva \\ ORCID: https://orcid.org/0000-0002-4233-7483 \\ Centro Universitário Uninovafapi, Brasil \\ E-mail: camila_roxo@hotmail.com \\ Yasmin Silva Moreira de Lucena \\ ORCID: https://orcid.org/0000-0001-6017-0608 \\ Centro Universitário do Maranhão, Brasil \\ E-mail: lyasilvamore7777@gmail.com \\ Sâmia Moreira de Andrade \\ ORCID: https://orcid.org/0000-0002-2310-2515 \\ Centro Universitário Santo Agostinho, Brasil \\ E-mail: samia.andrade27@hotmail.com \\ Matheus Hipólito do Nascimento \\ ORCID: https://orcid.org/0000-0003-0941-3955 \\ Faculdade Maurício de Nassau, Brasil \\ E-mail: mat.hipolito@hotmail.com \\ Evaldo Hipólito de Oliveira \\ ORCID: https://orcid.org/0000-0003-4180-012X \\ Universidade Federal do Piauí, Brasil \\ E-mail: evaldohipolito@gmail.com
}

\begin{abstract}
Resumo
A resina composta é um dos materiais odontológicos mais utilizados pelos profissionais, visando a busca da restauração estética e funcional dos dentes. Nesse contexto, este estudo objetivou verificar os fatores que influenciam na longevidade de restaurações diretas realizadas com resina composta. Foi realizado uma revisão de literatura do tipo integrativa, no qual o levantamento bibliográfico foi feito por meio de consulta em bases de dados de relevância para a produção do conhecimento em saúde: PubMed/Medline e SCIELO. Foram encontrados incialmente na busca 1177 artigos, que após os critérios de inclusão: publicações nos idiomas português e inglês, artigos na íntegra e publicados apenas no período de 2009 a 2019, bem como critérios de exclusão: estudos em outros idiomas, não disponíveis na íntegra, que não apresentassem relação com o tema abordado e fora do tempo estabelecido, totalizou-se 20 artigos. Conforme os artigos pesquisados, fraturas são relatadas em quase $100 \%$ dos estudos como motivo para falha de restaurações de resina composta, seguido de cárie secundária e a falta de higienização por parte do paciente. Já com relação aos principais fatores para longevidade da resina, os estudos demonstram que a escolha do material, o tamanho da cavidade, a utilização de material de barreira para prevenir patógenos orais como o isolamento absoluto, a necessidade do polimento e acabamento realizados de forma correta e sobretudo, a realização de um programa de profilaxia regular. Portanto, deve-se ter em mente que os esforços para diagnóstico, planejamento, indicação do tratamento, execução correta do procedimento, protocolo adesivo, observação dos aspectos oclusais, controle de biofilme e acompanhamento são essenciais para obter resultados que visam a longevidade da restauração direta.
\end{abstract}

Palavras-chave: Restauração dentária permanente; Longevidade; Materiais dentários. 


\begin{abstract}
Composite resin is one of the most used dental materials by professionals, aiming at the search for aesthetic and functional restoration of the teeth. In this context, this study aimed to verify the factors that influence the longevity of direct restorations. An integrative literature review was performed, in which the bibliographic survey was performed through consultation in databases of relevance to the production of health knowledge: PubMed / Medline and SCIELO, in Portuguese and English, in full, between January 2009 and January 2019, totaling 20 articles. According to the researched articles, fractures are reported in almost $100 \%$ of the studies as a reason for failure of composite resin restorations, followed by secondary caries and lack of hygiene by the patient. Regarding the main factors for resin longevity, studies show that the choice of material, the size of the cavity, the use of barrier material to prevent oral pathogens (absolute isolation), the need for proper polishing and finishing. and above all, the implementation of a regular prophylaxis program. Therefore, it should be borne in mind that efforts for diagnosis, planning, treatment indication, correct procedure execution, observation of occlusal aspects, biofilm control and follow-up are essential to obtain results aimed at direct restoration longevity.
\end{abstract}

Keywords: Permanent dental restoration; Longevity; Dental materials.

\title{
Resumen
}

La resina compuesta es uno de los materiales dentales más utilizados por los profesionales, con el objetivo de buscar la restauración estética y funcional de los dientes. En este contexto, este estudio tuvo como objetivo verificar los factores que influyen en la longevidad de las restauraciones directas realizadas con resina compuesta. Se realizó una revisión integradora de la literatura, en la cual se realizó el relevamiento bibliográfico consultando bases de datos relevantes para la producción de conocimiento en salud: PubMed / Medline y SCIELO, en portugués e inglés, en su totalidad, entre los períodos de enero de 2009 a enero de 2019, totalizando 20 artículos. Según los artículos investigados, las fracturas se reportan en casi el $100 \%$ de los estudios como motivo del fracaso de las restauraciones de resina compuesta, seguidas de caries secundarias y la falta de higiene por parte del paciente. En cuanto a los principales factores para la longevidad de la resina, los estudios muestran que la elección del material, el tamaño de la cavidad, el uso de material barrera para prevenir patógenos orales (aislamiento absoluto), la necesidad de pulido y acabado realizado correctamente y sobre todo, la realización de un programa de profilaxis regular. Por tanto, hay que tener en cuenta que los esfuerzos de diagnóstico, planificación, indicación del tratamiento, correcta ejecución del procedimiento, observación de los aspectos oclusales, control y seguimiento del biofilm son fundamentales para obtener resultados que apunten a la longevidad de la restauración directa.

Palabras clave: Restauración dental permanente; Longevidad; Materiales dentales.

\section{Introdução}

A resina composta é um material bastante utilizado por profissionais de odontologia com a finalidade de restaurar estética e funcionalmente os elementos dentários. É indicada para modificação da forma dos dentes, restauração de dentes fraturados, cariados e para a correção de imperfeições no esmalte dentário (Krämer et al., 2009).

Esse material é composto por uma matriz orgânica (monômeros dimetacrilatos), inorgânica (principalmente, quartzo, sílica coloidal e partículas de vidros), que possuem a função de melhorar as propriedades mecânicas do material e o agente de união (responsável pela associação das partículas de cargas à matriz orgânica, visando ampliar as propriedades mecânicas, diminuir a absorção de água e o coeficiente de expansão térmica linear) 9 Silveira et al., 2016) .

O progresso dos compósitos resinosos teve amplo destaque na década de 50, quando Buonocore, em 1955, revelou ao mundo a técnica do condicionamento ácido do esmalte, aperfeiçoando a aderência à estrutura dental. Posteriormente, no ano de 1956, Bowen introduziu no mercado, o Bis-GMA (Bisfenol Glicidil Metacrilato), o que melhorou as propriedades das resinas compostas, expandindo a sua indicação na prática odontológica (Opdam et al., 2010).

Na década de 70 houve várias mudanças em relação aos materiais restauradores estéticos. Em 1974, Cooley foi o primeiro cirurgião dentista a recobrir a face vestibular dos dentes anteriores com resina composta para recuperação da estética, a partir da descoberta dos aparelhos de luz ultravioleta em 1973 por Waller (Opdam et al., 2010; Pazinatto et al., 2012). Com o advento de novas tecnologias nas ciências dos materiais nos últimos anos, a qualidade das restaurações de resina composta foi aprimorada (Pallesen \& Dijken, 2015). Além disso, as modificações na composição do material, sobretudo em relação ao tamanho e distribuição das partículas de carga, melhoraram algumas de suas propriedades. Atualmente, existem, no mercado, vários tipos de resinas compostas que se diferenciam em sua composição, com cada uma apresentando, portanto, suas indicações 
e limitações (Pallesen \& Dijken, 2015).

Nesse sentido, o uso desse material aumentou consideravelmente em popularidade e previsibilidade, tornando-se rotina na prática odontológica (Correa et al., 2012). Assim, tem-se buscado a crescente melhoria das resinas compostas, visando facilitar a técnica e aumentar a longevidade das restaurações. Dessa forma busca-se garantir uma maior resistência da restauração às forças mastigatórias, uma lisura superficial, e a conservação da mesma por um maior período de uso clínico (Baldissera et al., 2013). Em relação à longevidade das restaurações de resina composta, ainda não há um entendimento claro dos fatores clínicos que podem influenciar o desempenho das restaurações. Além disso, alguns fatores relacionados ao paciente são os que mais influenciam a longo prazo, como dieta, higiene bucal, hábitos parafuncionais e oclusão (Baldissera et al., 2013). Esses fatores além de prejudicar a longevidade desse material, irão provocar problemas clínicos como: descoloração, manchas e acúmulo de placa e com isso, podem ter como consequência o desenvolvimento de doenças periodontais e cárie (Laske et al., 2016).

Levando em consideração que atualmente houve um crescimento quanto ao uso das resinas compostas, é de grande importância o estudo dos fatores que visam a conservação da estrutura dental e sobretudo os fatores que podem levar a falha dessas restaurações. Assim é relevante esclarecer sobre a importância dos fatores que contribuem para a longevidade desse material. Diante do exposto, o objetivo deste estudo foi verificar os fatores que influenciam na longevidade de restaurações diretas.

\section{Metodologia}

Foi realizada uma revisão de literatura do tipo integrativa, norteada na seguinte pergunta: quais fatores influenciam na longevidade das restaurações diretas de resina composta? O levantamento bibliográfico foi realizado por meio de consulta em bases de dados de relevância para a produção do conhecimento em saúde: PubMed/Medline e SCIELO, utilizando seguintes descritores cadastrados em Descritores em Ciência da Saúde (DECS): restauração dentária permanente, longevidade e materiais dentários, seus respectivos termos em inglês

Foram estabelecidos como critérios de inclusão: publicação nos idiomas português e inglês, artigos na íntegra; publicados no período entre janeiro de 2009 a janeiro de 2019. Já os critérios de exclusão foram estudos em outros idiomas, que não fossem em português e inglês, não disponíveis na íntegra, que não apresentassem relação com o tema abordado e fora do tempo estabelecido.

Utilizando-se os filtros "free full text" e "publication dates 10 years" e os termos Dental Restoration, Permanent, and Longevity obteve-se 47 artigos. Deste número foi realizado análise dos títulos, resumos e verificação dos critérios de inclusão e exclusão, verificou-se 38 obedeciam a tais critérios. Em seguida foi realizado a leitura na íntegra destes artigos e aplicou-se os critérios de inclusão e exclusão, obtendo-se 6 artigos. Estavam 8 artigos duplicados, 10 estavam fora do período estabelecido e 14 não abordavam a temática.

Em seguida utilizou-se os termos Dental Restoration, Permanent, and Longevity and Dental Materials e utilizou-se os mesmos filtros da busca anterior. Desta forma foram achadas 40 publicações. Destes artigos foram analisados os títulos e resumos e após aplicação dos critérios estabelecidos restaram 12 artigos, para análise na integra. Com relação à análise completa, verificou-se que 4 estavam em duplicatas e 4 não abordavam a temática, ficando somente 4 artigos para contemplar a revisão integrativa. No banco de dados da Scielo, na primeira pesquisa foram utilizados os três descritores em português com o operador booleano OR, foram encontrados 13 artigos, deste número verificou-se que 3 estavam em duplicata e 4 não abordavam a temática, excluindo 7 artigos. Restaram 6 publicações que foram lidas na íntegra e compuseram o estudo.

Uma segunda busca utilizou os descritores: restauração dentária permanente and longevidade. Foram encontrados 69 artigos, após a realização do filtro realizado de anos de publicação e idiomas, foram achadas 17 publicações. Destes artigos foram analisados os títulos, resumos e aplicação critérios estabelecidos, selecionou-se 12 artigos, para análise na integra. Com relação 
da análise completa, verificou-se que 3 estavam em duplicatas e 5 não abordavam a temática. Desta forma selecionou-se 4 artigos, totalizando 20 publicações para compor a revisão integrativa, conforme demonstrado no fluxograma (Figura 1).

Figura 1 - Seleção da amostra após a aplicação de critérios de inclusão e exclusão.

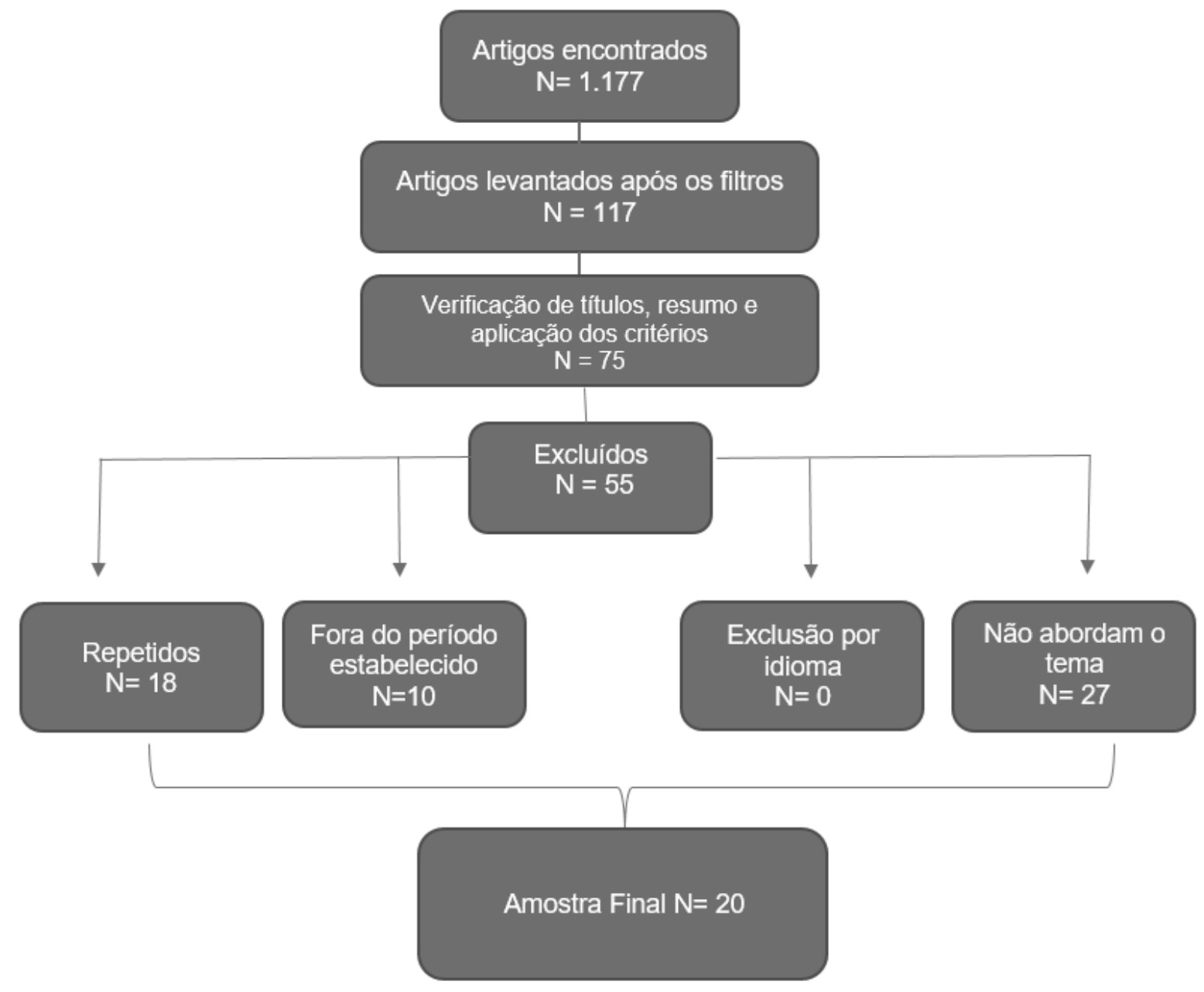

Fonte: Autores.

\section{Resultados e Discussão}

\subsection{Fatores para o desenvolvimento de falhas nas restaurações diretas}

As restaurações dentárias estão sujeitas a vários desafios no ambiente oral, visto que com o tempo, biofilmes de composição múltipla e habilidades cariogênicas se acumulam como um evento cíclico. Tensões ácidas, abrasivas e mecânicas de diferentes extensões e magnitudes durante a mastigação exercem desafios adicionais em restaurações compostas. Os processos de envelhecimento térmico, mecânico e químico afetam adversamente as restaurações e, em certos casos, levam a falhas, além de outros problemas (Krämer et al., 2009; Opdam et al., 2010). Nesse contexto, na Tabela 1, demonstra os principais causadores de falhas que diminuem a longevidade da restauração direta. 
Tabela 1 - Principais fatores para desenvolvimento de falhas que interferem na longevidade das restaurações diretas.

\begin{tabular}{|c|c|c|c|c|c|}
\hline Autor/ano & Objetivo & Amostra & $\begin{array}{l}\text { Período de } \\
\text { avaliação }\end{array}$ & $\begin{array}{l}\text { Tipo de } \\
\text { Estudo }\end{array}$ & $\begin{array}{l}\text { Resultados (principal fator da } \\
\text { falha) }\end{array}$ \\
\hline $\begin{array}{l}\text { Kramer et al. } \\
(2009)\end{array}$ & $\begin{array}{l}\text { Analisar clinicamente dois tipos diferentes } \\
\text { de resina composta em cavidades classe II } \\
\text { extensa por um período de } 4 \text { ano }\end{array}$ & 68 restaurações & 4 anos & $\begin{array}{l}\text { Estudo } \\
\text { Clínico }\end{array}$ & Fraturas \\
\hline $\begin{array}{l}\text { Opdam et al. } \\
(2010)\end{array}$ & $\begin{array}{l}\text { Comparar a longevidade de restaurações de } \\
\text { três a cinco faces entre amálgama e resina } \\
\text { composta em pacientes com risco de cárie }\end{array}$ & $\begin{array}{l}747 \\
\text { restaurações }\end{array}$ & 12 anos & $\begin{array}{l}\text { Estudo } \\
\text { Clínico }\end{array}$ & Cárie secundária \\
\hline $\begin{array}{l}\text { Silveira- } \\
\text { Pedrosa et al. } \\
(2016)\end{array}$ & $\begin{array}{l}\text { Avaliar a resistência à fratura de pré-molares } \\
\text { superiores com preparos cavitários extensos } \\
\text { submetidos a diferentes procedimentos } \\
\text { restauradores. }\end{array}$ & $\begin{array}{l}50 \\
\text { pré-molares } \\
\text { superiores } \\
\text { humanos } \\
\text { hígidos }\end{array}$ & $\begin{array}{l}\text { Curto } \\
\text { período }\end{array}$ & $\begin{array}{l}\text { Estudo } \\
\text { Clínico }\end{array}$ & Fratura \\
\hline $\begin{array}{l}\text { Correa et al. } \\
(2012)\end{array}$ & $\begin{array}{l}\text { Investigar os fatores paciente e dentário } \\
\text { associados à seleção de material restaurador } \\
\text { em restaurações posteriores diretas em } \\
\text { adultos jovens }\end{array}$ & 720 indivíduos & 20 anos & $\begin{array}{l}\text { Estudo } \\
\text { Clínico }\end{array}$ & $\begin{array}{l}\text { Os presentes achados sugerem que } \\
\text { variáveis relacionadas ao tipo de } \\
\text { serviço odontológico, cárie } \\
\text { dentária e características da } \\
\text { cavidade determinam a escolha dos } \\
\text { dentistas para os materiais } \\
\text { restauradores. Outras } \\
\text { características individuais, como } \\
\text { status demográfico } \\
\text { socioeconômico. }\end{array}$ \\
\hline $\begin{array}{l}\text { Pazinatto et } \\
\text { al. (2012) }\end{array}$ & $\begin{array}{l}\text { Avaliar a performance da resina composta } \\
\text { em restaurações classe I e II }\end{array}$ & 67 restaurações & $\begin{array}{l}4 \text { anos e } 8 \\
\text { meses }\end{array}$ & $\begin{array}{l}\text { Estudo } \\
\text { Clínico }\end{array}$ & Cárie secundária \\
\hline $\begin{array}{l}\text { Baldiserra et } \\
\text { al. (2013) }\end{array}$ & $\begin{array}{l}\text { Investigou a longevidade de restaurações } \\
\text { posteriores colocadas com } 3 \text { compósitos } \\
\text { universais (Charisma, Herculite XR, Z100) e } \\
\text { de restaurações anteriores colocadas com } 2 \\
\text { compósitos universais (Charisma, Herculite } \\
\text { XR). }\end{array}$ & 90 pacientes & 20 anos & $\begin{array}{l}\text { Estudo } \\
\text { Clínico }\end{array}$ & $\begin{array}{l}\text { Fratura. } \\
\text { As variáveis socioeconômicas e } \\
\text { comportamentais atuam } \\
\text { diretamente sobre a longevidade } \\
\text { das restaurações. }\end{array}$ \\
\hline $\begin{array}{l}\text { Pallesen e } \\
\text { Van Dijken } \\
(2015)\end{array}$ & $\begin{array}{l}\text { Avaliar a durabilidade de três compósitos de } \\
\text { resina convencional em restaurações de } \\
\text { Classe II durante } 27 \text { anos. }\end{array}$ & 30 indivíduos & 27 anos & $\begin{array}{l}\text { Estudo } \\
\text { Clínico }\end{array}$ & Cárie secundária \\
\hline $\begin{array}{l}\text { Laske et al. } \\
(2016)\end{array}$ & $\begin{array}{l}\text { Investigar a longevidade de restaurações } \\
\text { diretas feitas por um grupo cirurgiões- } \\
\text { dentistas gerais e explorar o efeito de fatores } \\
\text { relacionados à prática / operador, paciente e } \\
\text { dente / restauração na sobrevivência da } \\
\text { restauração. }\end{array}$ & $\begin{array}{l}\text { Arquivos de } 24 \\
\text { profissionais } \\
\text { de odontologia } \\
(359.548 \\
\text { restaurações) }\end{array}$ & 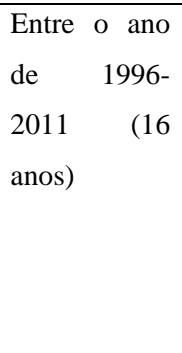 & $\begin{array}{l}\text { Estudo } \\
\text { Transversa } \\
1\end{array}$ & $\begin{array}{l}\text { Existe uma grande variação na taxa } \\
\text { anual de falha entre as diferentes } \\
\text { práticas odontológicas, variando } \\
\text { entre } 2,3 \% \text { e } 7,9 \% \text {. O perfil } \\
\text { socioeconômico dos pacientes } \\
\text { influenciou de forma indireta nas } \\
\text { falhas encontradas. }\end{array}$ \\
\hline $\begin{array}{l}\text { Casagrande } \\
\text { et al. (2017) }\end{array}$ & $\begin{array}{l}\text { Avaliar a longevidade e os fatores associados } \\
\text { às falhas de restaurações adesivas realizadas } \\
\text { em lesões de cárie profunda de molares } \\
\text { permanentes após remoção completa e } \\
\text { remoção seletiva de cárie. }\end{array}$ & 297 indivíduos & 36 meses & $\begin{array}{l}\text { Estudo } \\
\text { Clínico }\end{array}$ & Cárie e falta higiene oral \\
\hline
\end{tabular}


Fonte: Autores.

Fraturas são relatadas em quase $100 \%$ dos estudos como motivos para falhas de restaurações com resina compostas. As fraturas são um resultado da mecânica cíclica carregada que o complexo restaurador é submetido constantemente na boca. A fadiga é a principal razão que interfere a longo prazo, contribuindo para a deterioração intraoral do complexo restaurador. Estimulação mecânica constante, intensidade e duração variadas leva a crescimento de fendas na estrutura restaurada, que não possui os mesmos mecanismos de resistência de dentes sadios, resultando em uma gradual deterioração da força ao longo do tempo, significando que a carga que uma restauração pode suportar após anos de serviço clínico é muito menor do que nos primeiros dias após a colocação. Fratura de curto prazo também podem ocorrer devido a erros técnicos durante procedimentos clínicos, como erros na preparação da cavidade, deixando vazios dentro do compósito ou na anatomia final da restauração (Krämer et al., 2009; Silveira et al., 2016).

Contudo, vale ressaltar que desde que sejam tomados cuidados no diagnóstico, grandes falhas em restaurações de resina composta são improváveis de acontecer a curto prazo. A longo prazo, geralmente é mais provável que falhas ocorram, embora muitos estudos clínicos atuais indiquem que sob excelentes condições clínicas da resina, isso ocorra em um índice menor e a mesma pode durar bastante tempo (Silveira et al., 2016).

A literatura mostra claramente que a cárie secundária pode ser responsável por falhas na restauração. Estudos atuais reconhecem que o hábito alimentar baseado em alto consumo de açúcar é a principal causa de maior incidência de cárie na população em geral. No entanto, existem evidências clínicas que restaurações de resina composta mostraram risco aumentado de cárie secundária em comparação a restaurações de amálgama. Outro ponto a ser discutido sobre a recidiva de cárie é o forramento das cavidades. Acredita-se que o uso de ionômero de vidro reduza risco de cárie secundária devido à liberação de flúor, mas a maior evidência é que a ocorrência cárie secundária depende do nível de risco do paciente para desenvolvimento da cárie e não da presença do forramento (Opdam et al., 2010; Pallesen \& Dijken, 2015).

Outro fator importante para longevidade do material, segundo alguns estudos é a condição de higiene oral do indivíduo, exemplo disso seria que pacientes com gengivite demonstraram ter risco quase três vezes maior de falhas na restauração. Além disso, as variáveis socioeconômicas e comportamentais também podem afetar a longevidade das restaurações, pois a cárie dentária está associada diretamente aos aspectos sociais que ocorrem durante o curso da vida. É possível que esses aspectos possam influenciar a longevidade das restaurações (Correa et al., 2012; Laske et al., 2016).

Ressalta-se também que restaurações colocadas em consultórios odontológicos localizados em áreas com baixo nível socioeconômico mostraram taxas de falha mais altas do que as práticas localizadas em áreas de maior poder aquisitivo. A cárie secundária não foi relatada como principal motivo de falha nos estudos com pacientes de clínicas particulares com maior status econômico. Evidências de base populacional indicam que o tipo de pagamento dos serviços odontológicos está associado com a escolha de materiais restauradores pelos dentistas e as características socioeconômicas desse paciente (Correa et al., 2012; Casagrande et al., 2017).

\subsection{Fatores que possibilitam a longevidade da resina composta}

A longevidade de uma restauração direta está associada com o tempo que essa restauração permanece em boca de forma aceitável. Portanto, conhecer a longevidade e os fatores envolvidos é necessário, para que não ocorra a troca repetitiva de material, desgastando o dente e podendo ocasionar perda de tecido dentário sadio. Alguns fatores podem influenciar a longevidade de uma restauração com resina composta, que engloba também o diagnóstico correto do cirurgião-dentista, a higiene oral do paciente, a frequência com que se troca de dentista, o tipo e a localização do dente, o risco de cáries, de estresse oclusal, como bruxismo, e desordem temporomandibular (Rodolpho et al., 2011; Arunpraditkul et al., 2009). Nesse contexto, a tabela 2 
demonstra os principais fatores para a longevidade desse material odontológico.

Tabela 2 - Principais fatores para longevidade da restauração direta.

\begin{tabular}{|c|c|c|c|c|}
\hline Autor & Objetivo & Tipo de Estudo & Amostra & Resultados \\
\hline $\begin{array}{l}\text { Arunpraditkul, } \\
\text { Saengsanon, \& } \\
\text { Pakviwat } \\
\text { (2009) }\end{array}$ & $\begin{array}{l}\text { Avaliar a resistência à fratura de } \\
\text { dentes tratados } \\
\text { endodonticamente }\end{array}$ & $\begin{array}{l}\text { Estudo } \\
\text { transversal }\end{array}$ & $\begin{array}{l}32 \\
\text { indivíduos }\end{array}$ & $\begin{array}{l}\text { Os autores frisam a necessidade de verificar o tamanho da } \\
\text { cavidade, para que ocorra uma restauração mais eficaz. }\end{array}$ \\
\hline $\begin{array}{l}\text { Sunnegårdh- } \\
\text { Grönberg et al. } \\
\text { (2009) }\end{array}$ & $\begin{array}{l}\text { Investigar a seleção de materiais } \\
\text { restauradores diretos e a } \\
\text { longevidade das restaurações } \\
\text { substituídas em relação às } \\
\text { características do operador e do } \\
\text { paciente. }\end{array}$ & $\begin{array}{l}\text { Estudo } \\
\text { transversal }\end{array}$ & $\begin{array}{l}2834 \\
\text { pacientes }\end{array}$ & $\begin{array}{l}\text { A classe II foi a restauração e a substituição mais frequentes. } \\
\text { O risco de cárie e a experiência do operador influenciaram } \\
\text { a longevidade das substituições. }\end{array}$ \\
\hline $\begin{array}{l}\text { Rodolpho et al. } \\
\text { (2011) }\end{array}$ & $\begin{array}{l}\text { Investigou a longevidade das } \\
\text { restaurações posteriores }\end{array}$ & $\begin{array}{l}\text { Estudo } \\
\text { retrospectivo }\end{array}$ & $\begin{array}{l}61 \\
\text { pacientes }\end{array}$ & $\begin{array}{l}\text { As restaurações diretas tiveram desempenho clínico em } 22 \\
\text { anos, com taxa de falha anual de } 1,5 \% \text { (preenchida no meio) } \\
\text { e } 2,2 \% \text {. }\end{array}$ \\
\hline $\begin{array}{l}\text { Heintze \& } \quad \& \\
\text { Rousson } \\
(2012)\end{array}$ & $\begin{array}{l}\text { Revisão de estudos clínicos que } \\
\text { relatavam sobre a longevidade }\end{array}$ & $\begin{array}{l}\text { Revisão } \\
\text { sistemática }\end{array}$ & 115 & $\begin{array}{l}\text { As restaurações com resinas compostas híbrida e } \\
\text { microparticuladas, que foram colocadas com a técnica de } \\
\text { condicionamento ácido de esmalte e dique de borracha, } \\
\text { apresentaram o melhor desempenho geral; a longevidade } \\
\text { dessas restaurações era semelhante às restaurações de } \\
\text { amálgama. }\end{array}$ \\
\hline $\begin{array}{l}\text { Camacho et al, } \\
\text { (2013) }\end{array}$ & $\begin{array}{l}\text { Avaliar o efeito do peróxido de } \\
\text { carbamida a } 34 \% \text { e flúor fosfato } \\
\text { acidulado a } 1,23 \% \text { sobre duas } \\
\text { resinas compostas que } \\
\text { receberam dois tipos de } \\
\text { acabamento: } \\
\text { mecânico e matriz de poliéster }\end{array}$ & $\begin{array}{l}\text { Estudo } \\
\text { transversal }\end{array}$ & 42 corpos & $\begin{array}{l}\text { Os autores ressaltam a importância do polimento e } \\
\text { acabamento para longevidade da restauração. }\end{array}$ \\
\hline $\begin{array}{l}\text { Lawson et al. } \\
(2015)\end{array}$ & $\begin{array}{l}\text { Investigar o uso de dique de } \\
\text { borracha por cirurgiões- } \\
\text { dentistas }\end{array}$ & $\begin{array}{l}\text { Estudo } \\
\text { transversal }\end{array}$ & $\begin{array}{l}1716 \\
\text { profissiona } \\
\text { is }\end{array}$ & $\begin{array}{l}\text { Somente } 47 \% \text { dos profissionais utilizam o dique de } \\
\text { borracha para a realização da restauração. }\end{array}$ \\
\hline $\begin{array}{l}\text { Fernández et al. } \\
\text { (2015) }\end{array}$ & $\begin{array}{l}\text { Avaliar a longevidade dos } \\
\text { reparos } \\
\text { defeitos clínicos localizados em } \\
\text { restaurações de resina composta } \\
\text { que foram inicialmente } \\
\text { planejadas e tratadas como uma } \\
\text { substituição de restauração }\end{array}$ & Estudo clínico & $\begin{array}{l}28 \\
\text { pacientes }\end{array}$ & $\begin{array}{l}\text { O reparo de resinas compostas defeituosas como tratamento } \\
\text { alternativo visando aumentar sua longevidade provou ser } \\
\text { um tratamento seguro e eficaz a longo prazo. }\end{array}$ \\
\hline $\begin{array}{l}\text { Rodolpho et al. } \\
\text { (2017) }\end{array}$ & $\begin{array}{l}\text { Investigar a influência de } \\
\text { variáveis independentes na } \\
\text { longevidade de restaurações } \\
\text { extensas de resina composta em } \\
\text { até } 15 \text { anos de acompanhamento }\end{array}$ & $\begin{array}{l}\text { Estudo clínico } \\
\text { retrospectivo }\end{array}$ & $\begin{array}{l}97 \\
\text { pacientes }\end{array}$ & $\begin{array}{l}\text { As variáveis relacionadas ao tipo de dente e localização no } \\
\text { arco foram significativas na sobrevivência de restaurações } \\
\text { extensas de resina composta em até } 15 \text { anos de } \\
\text { acompanhamento. }\end{array}$ \\
\hline $\begin{array}{l}\text { Estay et al. } \\
(2018)\end{array}$ & $\begin{array}{lr}\text { Avaliar } & \text { clinicamente } \\
\text { restaurações } & \text { posteriores }\end{array}$ & $\begin{array}{l}\text { Estudo } \\
\text { transversal }\end{array}$ & $\begin{array}{l}34 \\
\text { pacientes }\end{array}$ & $\begin{array}{l}\text { Após } 12 \text { anos, todos os grupos se comportaram de maneira } \\
\text { semelhante em adaptação marginal, coloração marginal, }\end{array}$ \\
\hline
\end{tabular}




\begin{tabular}{|c|c|c|c|c|}
\hline & $\begin{array}{l}\text { reparadas de amálgama e } \\
\text { compostos por um período de } 12 \\
\text { anos, investigar a influência do } \\
\text { reparo na sobrevivência das } \\
\text { restaurações e comparar seu } \\
\text { comportamento em relação aos } \\
\text { controles. }\end{array}$ & & & sensibilidade dentária, forma anatômica e brilho. \\
\hline $\begin{array}{l}\text { Kohli et al. } \\
(2019)^{19}\end{array}$ & $\begin{array}{l}\text { Comparar o sucesso de } \\
\text { materiais restauradores de resina } \\
\text { composta e amálgama em } \\
\text { pacientes pediátricos }\end{array}$ & $\begin{array}{l}\text { Estudo } \\
\text { transversal }\end{array}$ & 40 crianças & $\begin{array}{l}\text { Ambos os materiais restauradores foram igualmente } \\
\text { eficazes na restauração da dentição decídua. }\end{array}$ \\
\hline $\begin{array}{l}\text { Massano et al. } \\
(2019)^{20}\end{array}$ & $\begin{array}{l}\text { Avaliar a longevidade das } \\
\text { restaurações de Classe III / IV } \\
\text { realizadas com diferentes } \\
\text { compósitos de resina }\end{array}$ & $\begin{array}{l}\text { Estudo } \\
\text { transversal }\end{array}$ & $\begin{array}{l}53 \\
\text { pacientes }\end{array}$ & $\begin{array}{l}\text { As resinas compostas apresentaram boa longevidade clínica } \\
\text { nas restaurações diretas anteriores, quando aplicada de } \\
\text { forma correta quando seguida conforme as instruções do } \\
\text { fabricante. }\end{array}$ \\
\hline
\end{tabular}

Fonte: Autores.

Com base nas características e propriedades fornecidas pelas resinas compostas, é possível escolher o material ideal para cada tipo de situação. No entanto, para que uma restauração seja considerada satisfatória, é necessário, além de entender as propriedades do material, familiarizar-se com as técnicas de preparação da cavidade, respeitando os protocolos dos materiais utilizados e, em seguida, obter o sucesso clínico das restaurações (Heintze \& Rousson, 2011; Camacho et al., 2013).

Alguns estudos ressaltam a importância do tamanho da cavidade, pois o menor volume de superfície e cavidade composta pela resina está associado a uma melhor dissipação das tensões mecânicas na estrutura dental. Este fator é um dos mais relevantes referente a preservação da longevidade das restaurações, em detrimento de outras variáveis a nível de dente, visto que as fraturas são mais prováveis de acontecer em restaurações maiores, uma vez que uma maior quantidade de estrutura dental é removida e a resistência global dos dentes restaurados é reduzida (Rodolpho et al., 2011; Arunpraditkul et al., 2009).

Uma estrutura dental mais sólida significa maior resistência à deformação e propagação de fissuras. Importante para a longevidade é a manutenção margens de esmalte circundantes, baixa relação entre istmo e distância intercuspidal e preservação de infiltrações marginais (Heintze \& Rousson, 2011; Camacho et al., 2013). Ressalta-se também que a quantidade de esmalte na parede cervical influencia no selamento, pois se houver menos esmalte, interfere no processo de adesão (Lawson et al., 2015).

Logo, ressalta-se a importância da utilização do dique de borracha na realização do tratamento endodôntico, visto que a sua finalidade é de barreira para prevenir patógenos orais de entrar no dente acessado e a prevenção da inalação de instrumentos e soluções irrigadoras. E também casos de deglutição ou aspiração de instrumentos no trato gastrointestinal ou pulmão durante o tratamento (Camacho et al., 2013; Rodolpho et al., 2017).

Ressalta-se também a importância da técnica de controle de umidade na qualidade das restaurações em dentes tratados endodonticamente para conservar um ambiente não contaminado dentro do sistema de canais radiculares, pois a contaminação por saliva poderá resultar no desenvolvimento de patógenos orais dentro da câmara pulpar, e então essas bactérias se alimentam dos produtos de decomposição dos materiais restauradores, levando a infiltração coronária e a recontaminação bacteriana do conduto radicular (Rodolpho et al., 2017).

Cita-se também a necessidade do polimento e acabamento realizados de forma correta, pois essas ações melhoram a qualidade e longevidade das restaurações com resina, visto que a obtenção de uma superfície polida, irá reduzir o acúmulo de biofilme dental e consequentemente evitará a pigmentação (Camacho et al., 2013). Ressalta-se que a posição do dente ou tipo de dente também afeta a longevidade da restauração, visto que as restaurações em pré-molares geralmente têm se mostrado com 
melhor desempenho em relação aos molares, devido às cargas que os dentes molares precisam suportar (Rodolpho et al., 2011).

Cumpre lembrar, que atualmente existe evidencias que a reparação em restaurações de resina composta oferece grande benefícios na longevidade das restaurações. Portanto, deve-se avaliar quando existe uma falha localizada em parte da restauração, a probabilidade de escolher pelo reparo e reintervenções minimamente invasivas para restaurar a funcionalidade do conjunto dente-restauração. O reparo tem sido praticado e ensinado em muitas universidades, sendo um procedimento indicado para todos os casos, desde que a indicação esteja correta (Rodolpho et al., 2017).

Com relação ao tempo, a longevidade das resinas compostas, geralmente é inferior a 10 anos, o que pode significar uma decisão de tratamento precoce reparar resina composta defeituosa devido a alguma lesão de cárie localizada ou problema causado por dano mecânico. Logo, é importante a ida ao consultório odontológico periodicamente e se necessário realização a substituição da restauração (Fernández et al., 2015).

Cita-se a necessidade da realização de um programa de profilaxia regular, visto que o mesmo contribui para a durabilidade das restaurações e reduz o desenvolvimento de cárie secundária, como foi relatado anteriormente, o risco de cárie dos pacientes que influencia significativamente na longevidade das restaurações (Sunnegårdh-Grönberg et al., 2009).

Por fim, acredita-se que o profissional responsável pelo diagnóstico, indicação de tratamento, preparação das cavidades e aplicação dos materiais e técnicas é um fator significativo na longevidade da restauração. Além disso, para obter alta durabilidade dos tratamentos, é importante ter preparos dentais bem confeccionados, indicação precisa dos materiais restauradores, uso correto das técnicas e equipamentos de qualidade (Estay et al., 2018; Kohli et al., 2019).

Contudo, mesmo com extremo cuidado, a longevidade deste material, não é garantido e a reintervenção é frequentemente necessária. É necessário instruir o paciente, sobre a importância da higiene oral e a ida ao consultório odontológico periodicamente, visto que as condições impostas pelo ambiente oral, provavelmente poderá desencadear falhas. Boa comunicação entre o profissional e o paciente é sempre importante (Estay et al., 2018; Massano et al., 2019).

Vale lembrar que hoje temos grandes variedades de materiais de múltiplas propriedades mecânicas, várias composições e um evidente comprometimento com a estética. Devido à ampla gama de marcas no mercado, ampliou-se a competitividade entre as empresas o que resulta em maiores investimentos para desenvolver um material que melhore características como contração de polimerização e resistência ao desgaste. Outro fator importante seria a colaboração do paciente durante a execução dos procedimentos clínicos, além de seus hábitos e sua motivação em termos de saúde e higiene, também influencia na longevidade. Por isso, tanto a condição inicial da saúde oral quanto às limitações e dificuldades encontradas durante o tratamento devem ser reportadas nas descrições dos atendimentos, para identificar futuros problemas com os procedimentos realizados (Massano et al., 2019).

\section{Considerações Finais}

Os principais fatores que afetam a longevidade de restaurações de resina composta incluem fatores socioeconômicos, variáveis comportamentais, fraturas e cárie secundária. Deve-se saber que diagnóstico adequado, planejamento, indicação de tratamento, observação dos aspectos oclusais, controle de biofilme e acompanhamento são essenciais para obtenção de maior longevidade da resina composta.

Além disso, a higiene oral é um fator crucial para a longevidade das restaurações do paciente. É de extrema importância que o cirurgião-dentista instrua o paciente sobre a importância desse fator, além de frisar a necessidade do retorno ao consultório odontológico periodicamente. Vale ressaltar que, com a evolução dos materiais dentários, cada vez mais as resinas compostas vêm sendo melhoradas quanto a sua resistência e durabilidade no uso clínico, portanto mais estudos são necessários avaliando as novas resinas que entram no mercado e possuem características promissoras no tratamento clínico-restaurador. 


\section{Referências}

Arunpraditkul, S., Saengsanon, S., \& Pakviwat, W. (2009). Fracture resistance of endodontically treated teeth: three walls versus four walls of remaining coronal tooth structure. J. Prosthod., Philadelphia, 18(1): 49-53.

Baldissera, R. A. et al. (2013). Are there universal restorative composites for anterior and posterior teeth?. Journal of dentistry, 41(11): 1027-1035.

Camacho, G. B. et al. (2013). Avaliação da rugosidade superficial de resinas compostas expostas a diferentes agentes. Revista de Odontologia da UNESP; 37(3), 211-216.

Casagrande, L. et al. (2017). Longevity and associated risk factors in adhesive restorations of young permanent teeth after complete and selective caries removal: a retrospective study. Clin Oral Investig. 21(3):847-55.

Correa, M. B. et al. (2012). Amalgam or composite resin? Factors influencing the choice of restorative material. Journal of Dentistry, 40(9): 703-710.

Estay, J. et al. (2018). 12 years of repair of amalgam and composite resins: a clinical study. Operative dentistry, 43(1): 12-21.

Fernández, E. et al. (2015). Can repair increase the longevity of composite resins? Results of a 10-year clinical trial. Journal of dentistry, 43 (2): 279-286.

Heintze, S. D., Rousson, V. (2012). Clinical effectiveness of direct class II restorations-a meta-analysis. J Adhes Dent, 14(5): 407-31.

Kohli, A. et al. (2019). Assessment of longevity of composite and amalgam restorations in posterior teeth of paediatric patients: A comparative study. Journal of Advanced Medical and Dental Sciences Research, 7(1): 25-27.

Krämer, N. et al. (2009). Nanohybrid vs. fine hybrid composite in Class II cavities: clinical results and margin analysis after four years. Dental Materials, 25(6): $750-759$.

Laske, M. et al. (2016). Longevity of direct restorations in Dutch dental practices. Descriptive study out of a practice based research network. $J$ Dent. $46(1)$ : $12-$ 7 .

Lawson, N. C., Gilbert, G. H., Funkhouser, E., Eleazer, P. D., Benjamin, P. L. \& Worley, D. C. (2015). General dentists' use of isolation techniques during root canal treatment: from the national dental practicebased research network. Journal of Endodontics; 41(8): 1219-1225.

Massano, G. et al. (2019). Direct Composite Restorations of Anterior Teeth: A Retrospective Clinical Study. Journal of Adhesive Dentistry, 21(5);1-9.

Opdam, N. J. M. et al. (2010). 12-year survival of composite vs. amalgam restorations. Journal of dental research, 89(10), $1063-1067$.

Pallesen, U. \& Van Dijken, J. W. (2015). A randomized controlled 27 years follow up of three resin composites in Class II restorations. J Dent. Dec; 43(12):154758 .

Pazinatto, F. B. et al. (2012). 56-month clinical performance of Class I and II resin composite restorations. Journal of Applied Oral Science, 20(3): 323-328.

Pereira A. S. et al. (2018). Metodologia da pesquisa científica. [free e-book]. Santa Maria/RS. Ed. UAB/NTE/UFSM.

Rodolpho, P. A. R. et al. (2017). Longevidade de restaurações extensas de resina composta em dentes posteriores. Clínica - International Journal of Brazilian Dentistry, Florianópolis; 13(3): 228-237, jul./set.

Rodolpho, P. R. et al. (2011). 22-Year clinical evaluation of the performance of two posterior composites with different filler characteristics. Dental Materials, 27(10): 955-963.

Silveira, P. D. M. et al. (2016). Resistência à fratura de pré-molares com preparos extensos do tipo inlay submetidos a diferentes procedimentos restauradores. Oral Sciences, 3(1): 6-11.

Sunnegårdh-Grönberg, K. et al. (2009). Selection of dental materials and longevity of replaced restorations in Public Dental Health clinics in northern Sweden. Journal of dentistry, 37(9): 673-678. 